\title{
Mielopatía POR Enfermedad de DeVic: PRESENTA- CIÓN DE UN CASO Y REVISIÓN DE LA LITERATURA
}

\author{
Myelopathy Devic disease: case report and review of literature
}

${ }^{1}$ Facultad de Medicina Dr. Aurelio Melean, Universidad Mayor de San Simón, Cochabamba-Bolivia

Correspondencia a: Rocío Condori Bustillos Correo electrónico:rocio_all_ right@hotmail.com

Palabras clave: Neuritis Óptica, Mielitis transversa, Inmunoglobulina $\mathrm{G}$, Acuaporina 4

Keywords: Tneuritis, transverse myelitis, Immunoglobulin G, aquaporin 4 .

Procedencia y arbitraje: no comisionado, sometido a arbitraje externo.

Recibido para publicación: 015 de Septiembre del 2016 Aceptado para publicación 09 de Diciembre del 2016

Citar como: Rev Cient Cienc Med 2015; 19 (2): 48-54

\section{Rocío Condori Bustillos Mauricio ${ }^{1}$ Ramiro Cortez Chávez ${ }^{1}$ Juan Mauricio Ramos Morale Wilfredo Erick Rodríguez Sandoval ${ }^{1}$}

\section{RESUMEN}

a neuromielitis óptica, también conocida como enfermedad de Devic, es una enfermedad desmielinizante cuya prevalencia es muy baja. Se caracteriza por la inflamación y creación de anticuerpos contra el sistema nervioso central, respetando el cerebro pero comprometiendo el nervio óptico y dando alteraciones medulares. La presencia de anticuerpos de suero: acuaporina-4 de inmunoglobulina $\mathrm{G}$ es la razón por la que se diferenció de la esclerosis múltiple, del cual antes formaba parte como una variante de presentación clínica. El cuadro clínico de esta enfermedad se caracteriza por perdida de agudeza visual y mielitis transversa.

Caso Clínico:Se presenta el caso de una paciente investigada por un periodo de aproximadamente 5 meses de duración sin factores de riesgo, acude a la Caja Petrolera de Salud por presentar dolor en región lumbar izquierda, de tipo opresivo, de alta intensidad y dificultad para pararse acompañada de paresia aguda de extremidad inferior izquierda, sin mejoría aún después de la administración de Quetorol@. Después de descartar varias enfermedades se llegó al diagnóstico de un posible diagnóstico de mielopatía asociada con la enfermedad de Devic.

Discusión: Esta enfermedad es muy heterogénea en su presentación, por lo que los criterios diagnósticos se modificaron y se llegó a un nuevo consenso: La nueva nomenclatura define el término unificador Neuromielitis Óptica y el de Trastornos del espectro de Neuromielitis Óptica, que se estratifica aún más por las pruebas serológicas correspondientes a esta paciente apoyadas también en Resonancia Magnética; identificando este caso por métodos de exclusión.

\section{ABSTRACT}

Neuromyelitis Optica, also known as Devic's disease, is a demyelinating disease whose prevalence is very low; it is characterized by inflammation and the creation of antibodies against the central nervous system, respecting the brain but compromising the optic nerve and spinal cord changes giving. The presence of serum antibodies: aquaporin-4 immunoglobulin $\mathrm{G}$ is the reason why it differed from multiple sclerosis which was formerly part as a variant of clinical presentation. The clinical picture of this disease is characterized by loss of visual acuity and transverse myelitis.

Clinical case: the case of a patient investigated for a period of approximately 5 months with no risk factors, goes to Caja Petrolera de Sauld because of pain in the left lumbar region, oppressive type, high intensity and difficulty is presented stand accompanied by acute left lower extremity paresis, with no improvement even after administration of Quetorol ${ }^{\circledR}$, after discarding several diseases led to the diagnosis of a possible diagnosis of myelopathy associated with Devic's disease.

Discussion:This disease is very heterogeneous in its presentation, so the diagnostic criteria were modified and reached a new consensus: The new nomenclature defines the unifying term Neuromyelitis Optica and Neuromyelitis Optica Spectrum Disorder, which stratifies more by serological tests for this patient also supported by Magnetic Resonance; identifying this case exclusion methods.

\section{INTRODUCCIÓN}

T a neuromielitis óptica (NMO) -también conocida como Enfermedad de Devic- es una enfermedad desmielinizante inflamatoria idiopática autoinmune que ataca del sistema nervioso central, afectando preferencialmente los nervios ópticos y la medula espinal, respetando el cerebro, produciendo 
en estos lugares trastornos de la agudeza visual perdida de la función motora medular ${ }^{1}$. En 1894, Eugéne Devic describió por primera vez a la enfermedad ahora conocida como NMO con un reporte aproximado de 17 casos, tomando en cuenta antecedentes de estudios de asociación por otros autores hace 20 años atrás. Desde 1936, el síndrome de Devic se asoció como una variante de la esclerosis múltiple, con el fin de buscar una causa sobre esta enfermedad, sin embargo en 2004 Bergamaschi y Ghezzi la diferencian de la Esclerosis Múltiple (EM) y que la NMO puede asociarse con enfermedades autoinmunes específicas diferentes a la esclerosis múltiple ${ }^{2}$. La NMO presenta una distribución mundial con bajos niveles de prevalencia, es más frecuente en mujeres que en hombres con una relación 9:1 y afecta a jóvenes o adultos entre 30 años y 40 años. Algunas revisiones en la literatura establecen dos picos a la edad de 10-15 años y otro a los 45 años, presentándose con más incidencia en americanos, asiáticos, caucásicos, africanos y mediterráneos1. Suele asociarse a procesos autoinmunes como lupus eritematoso sistémico, tiroiditis de Hashimoto, síndrome de Sjögren (10\%-40\%), o infecciosos como tuberculosis3. Esta enfermedad se debe a la presencia de autoanticuerpos séricos, antiacuaporina-4 (anti-AQP4), también llamados NMO-IgG, producidos por las células B frente a un estímulo desconocido. Estos anticuerpos atacan a los canales de agua AQP4 que predominan en el sistema Nervioso Central (SNC) y que están normalmente en los astrocitos; particularmente en las zonas en íntimo contacto con el líquido cefalorraquídeo (LCR), como es el propio tejido ependimario Dichos anticuerpos son un marcador muy sensible y con especificidad alta para la NMO, presentándose en promedio en el $75 \%$ de los casos, siendo considerado como un criterio de diagnóstico para diferenciarla de la EM donde no existen dichos anticuerpos ${ }^{1,2}$. El cuadro clínico consiste en pérdida de la agudeza visual y mielitis transversa (con cuadriparesia o paraparesia, alteraciones sensitivas, disfunción esfinterianas, retención urinaria, espasmos y dolor en la región cervical y/o lumbar); la mielitis puede ser parcial o total, pero el criterio diagnóstico exige que en la resonancia magnética se encuentre compromiso longitudinal de por lo menos tres segmentos medulares (hipointensidades en T1 e hiperintensidades en T2), por lo general, la resonancia cerebral será normal, aunque ocasionalmente pueden encontrarse lesiones hipotalámicas (hasta 10\% de los pacientes) 1. Debido a su baja frecuencia, alta complejidad en el diagnóstico y la diferenciación de este cuadro de otras enfermedades similares, se presenta el caso de una paciente in- vestigada durante un periodo de 5 meses, sin factores de riesgo, ni antecedentes familiares y personales, con un posible diagnóstico de enfermedad de Devic, con el objetivo de informar y revisar los métodos diagnósticos de la misma, ya que dicha enfermedad tiene su origen en un defecto genético que produce la formación anómala de anticuerpos que atacan a los tejidos propios de la persona que expresan los antígenos susceptibles, produciendo un daño progresivo en estos, lo cual lleva al paciente a un deterioro neurológico en su mayoría grave.

\section{PRESENTACIÓN DEL CASO}

Motivo de consulta: dolor de espalda y dificultad para caminar.

Paciente femenino de 13 años de edad que acude a la caja petrolera de Salud de la Ciudad de Cochabamba-Bolivia, referido del Hospital México de Sacaba, por presentar: dolor de espalda y dificultad para pararse sin mejoría aun después de la administración de Quetorol ${ }^{\circledast}$. Dicho cuadro clínico de aproximadamente 8 horas de evolución es caracterizado por: dolor en región lumbar izquierda, de tipo opresivo, de alta intensidad, que se irradia a región del flanco izquierdo, se acompaña de paresia de extremidad inferior izquierda, con dificultad para deambular; refiere fiebre no cuantificada con escalofríos y traspiración profusa , niega otras sintomatologías.

Al Examen físico: Paciente álgida, consciente, orientado en las tres esferas, mucosas húmedas y rosadas. Signos vitales dentro de los valores normales: tono y trofismo muscular de miembros inferiores conservados, Debilidad para la flexión de la rodilla y flexión dorsal de pie Izquierdo. Babinski izquierdo, Banda de Disestesia D8 -D10 izquierda, llenado capilar de 2 seg. Sin edemas en miembros inferiores.

Se le solicitan: Hemograma: Hb: 11,1g/dl, HCM: 28,3 Fl., VCM: 83,7 Pg, Glóbulos Blancos: 5,03 cel/ ml, Neutrofilos: 3,38 \%. Examen General de orina: nada relevante; Radiografía de columna Lumbosacra sin evidencias de Lesión.

Ecografía pélvica: útero en anteversoflexión (AVF) conservado, ovarios de aspecto normal, vejiga de paredes normales. Ecografía de abdomen: todo normal sin relevancia, aparenta lesión quística en ovario derecho.

Con la presunción de Diagnóstico de una neuropatía del Ciático Poplíteo externo se realizó una electromiografía: que revela Radiculopatía L5 Izquierda, donde la velocidad de conducción motora y sensitiva distal y proximal del nervio peroneo Izquierdo Muestran Normalidad. Onda F ausente estimulando 
el nervio peroneo Izquierdo.

Se ha realizado tomografía de Columna Lumbar para descartar lesión de Canal. Las imágenes muestran protrusión discal L5-S1 que no explica la presencia de Babinski Izquierdo (Ver Figura 1), por lo cual se ha solicitado Resonancia Nuclear Magnética de médula, que muestra lesión laminar extensa en: D6D9 y otra de D9-D12 (Ver Figura 2 y 3 ). Los estudios de Tomografía Axial Computarizada (TAC) y Resonancia Magnética (RM) cerebrales son normales.

Se tomaron como Diagnósticos diferenciales:

-Neuropatía del Ciático Poplíteo Externo Izquierdo: Por la debilidad para dorsiflexión, eversión del pie, originando caída del mismo (pie péndulo) y dolor en la región anterolateral de la pierna y parte lateral del dorso del pie, los cuales empeoran con la actividad4. Con presunción de causa compresiva se solicitó: Ecografía de partes blandas en muslo Izquierdo y electromiografía: el cual no evidencia anormalidad y ante la presencia en la paciente de Babinsky se descartó dicho cuadro.

-Radiculopatía L5 izquierda por Hernia discal L5S1: Por la debilidad a la flexión plantar de pie y dedos

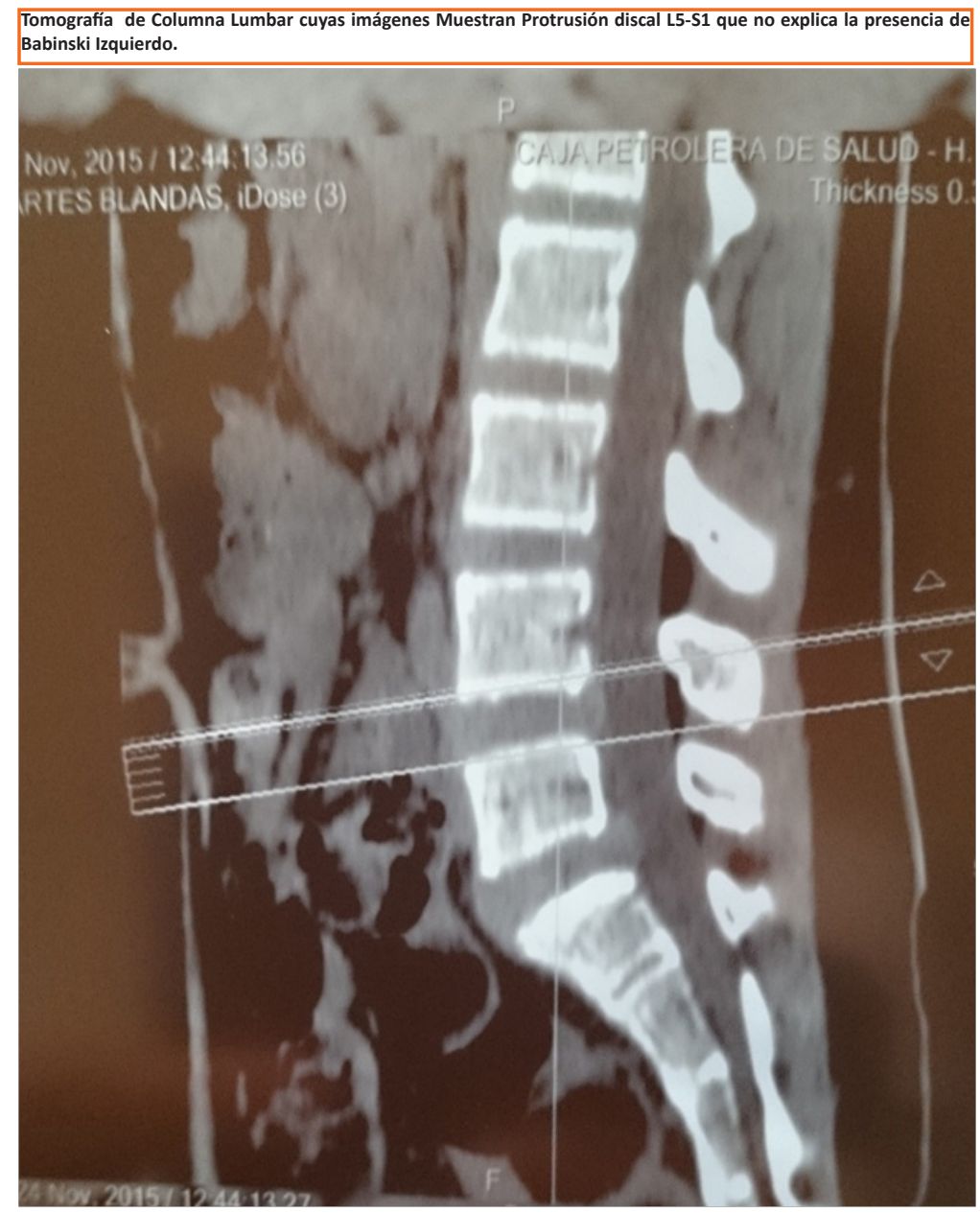

como al ponerse de puntillas (caída de pie), pérdida sensitiva en las partes laterales del pie y de los dos dedos extremos del pie y el hallazgo electromiográfico con ausencia de la onda F con estímulo a nivel peroneo (lo cual sugiere lesión en médula y no en raíces espinales) y presencia de signos de lesión de neurona motora central: se descarta dicho cuadro a pesar de la leve protrusión discal el L5 - S1 identificada en la TAC de Columna Lumbar.

-Mielopatía Dorsal como causa de síndrome de motoneurona superior: Por la debilidad motora no explicable en miembro inferior izquierdo acompañado de Babinsky por lo cual se solicitó RM: encontrándose hiperintensidad medulares laminares, fusiforme y longitudinal, y extensa (más de tres segmentos medulares) en secuencias potenciadas en $\mathrm{T} 2$, lo cual es sugerente de lesión desmielinizante laminar; hallazgo probablemente asociado a NMO o clasificadas como idiopáticas. Pero al tener la mielopatía dorsal una evolución crónica y por lo general, no recurrente se descarta dicha patología5.

-EM: Por la presencia de lesiones desmielinizantes en médula espinal. Pero ante la ausencia de signos y síntomas que involucran el compromiso de motoneurona superior y la ausencia de lesiones en RM cerebral (como ser lesiones periventriculares) y lesiones de corto segmento en la medula espinal6, además que según la literatura la frecuencia mayor de la EM inicio es a partir de los 29 años, y la paciente presentando 13 años de edad, se descartó dicha patologia1,3. Sin embargo, se ha descrito que algunos pacientes con EM que cursaban paralelamente con neuritis óptica y ataque parcial de mielitis, tienen una RM Cerebral sin anormalidades, la cual cumple con los criterio iniciales de la NMO7.

-Dentro del protocolo de estudio de mielopatias se tomó en cuenta la infección por Virus de la Inmunodeficiencia Humana (VIH) y como complicación de esta la Mielopatía Vacuolar; que ocasiona que la vaina protectora de mielina se desprenda de las células nerviosas de la médula espinal, debido a la formación pequeños agujeros llamados vacuolas en las fibras nerviosas8, los síntomas incluyen piernas débiles y rígidas e inestabilidad para caminar. La marcha se dificulta a medida que evoluciona la enfermedad. Algunos pacientes también contraen demencia del Síndrome de Inmunodeficiencia Adquirida (SIDA). La mielopatía vacuolar puede afectar hasta al 30\% de los pacientes adultos con SIDA no tratados, y su incidencia puede ser aún mayor en los niños infectados con $\mathrm{VIH}$, pero en este caso ante el negativo del ELISA se descarta dicha patología.

Se identificó este caso, por métodos de exclusión, como diagnóstico probable la mielopatía asociada 
con la enfermedad de Devic.

Durante la internación, el tratamiento postcrisis se administró: Metilprednisolona endovenosa en 5 pulsos de $500 \mathrm{mg}$ por día con posterior mejoría de la fuerza muscular de miembro inferior izquierdo pero con secuelas a la dorsiflexion, la paciente fue dada de alta tras 8 días de internación en buen estado general.
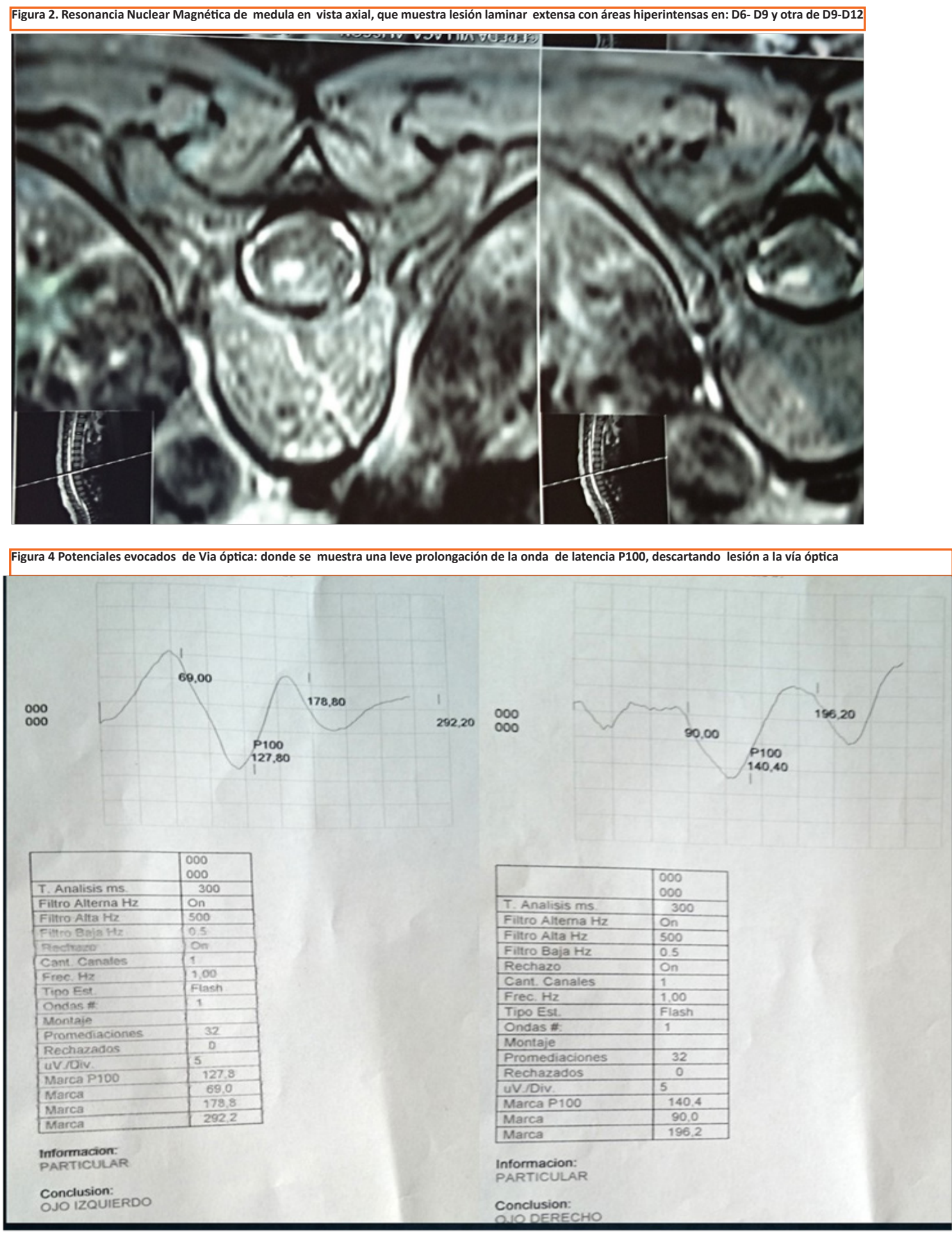
Criterios absolutos

$\checkmark \quad$ Neuritis óptica.

$\checkmark \quad$ Mielitis aguda.

$\checkmark \quad$ Ausencia de enfermedad por fuera del nervio óptico y la médula espinal.

\section{Criterios complementarios mayores}

$\checkmark$ Ac AQ4

$\checkmark \quad$ RM cerebral negativa.

$\checkmark \quad$ RM médula espinal con lesiones que comprometen tres o más cuerpos vertebrales.

$\checkmark \quad$ LCR con pleocitosis ( $\geq 50$ leucocitos o cinco neutrófilos $/ \mathrm{mm} 3$ ).

Tabla 2. Fuente: Diagnóstico de Sociedad de Ciencias Neurológicas Europeas NMO; elaborado por los autores de este trabajo.

\section{CRITERIOS DIAGNÓSTICOS PARA NMOSD SIN IGG-AQP4 Relación con el paciente estudiada O CON TEST SEROLÓGICO DESCONOCIDO}

1. Dos o más de los síndromes clínicos principales presentados 1. en uno o más eventos clínicos, más todos los siguientes requerimientos:

a) Al menos uno de los síndromes clínicos debe ser neuritis óptica, mielitis longitudinal aguda, o síndrome de área 2 . postrema.

b) Mostrar diseminación en espacio (Dos o más síndromes clínicos principales diferentes).

c) Cumplir requerimientos radiológicos adicionales.

2. Test negativo para IgG-AQP4 con el mejor método de detección disponible, o serostatus desconocido (no disponibilidad de metodología).

3. Descartar diagnósticos alternativos

\section{DISCUSIÓN}

La NMO es una rara enfermedad autoinmune desmielinizante de afectación al nervio óptico y médula espinal. Entidad hasta ahora diferenciada de la EM debido a un marcador sérico altamente específico: los anticuerpos AQP4 IgG (presente en el 60 a 90\% de pacientes), los cuales reaccionan específicamente a) Cuadro de mielitis aguda

c) Patrón de desmielinizacion lineal sugestivo de la enfermedad

\section{2.}

Por ausencia de pruebas confirmatorias en Bolivia no realizada

3.

Se descartó esclerosis múltiple mediante RM por ausencia de lesiones en cerebro $Y$ patrón de desmielinizacion lineal no sugestivo de esta enfermedad 
za en el endotelio del espacio perivascular en donde acontece la fijación del complemento y la cascada inflamatoria con macrófagos, eosinófilos y linfocitos aumentando la permeabilidad de BHE y así emergen los anticuerpos en suero. La sustancia gris se ve alterada secundariamente por el edema y la inflamación de sustancia blanca ${ }^{2,7}$. Dicha enfermedad se caracteriza por que hay múltiples ataques uni o bilaterales de neuritis óptica y mielitis aguda, los episodios entre ambos cuadros están en su mayoría separados por semanas, meses o años. Como los anticuerpos AQP4 no afectan la sustancia blanca ni oligodendrocitos, no se produce síntomas encefálicos; pero la afección de la médula cervical puede producir náuseas, hipo o incluso falla respiratoria ${ }^{3}$. Según estudios dichos anticuerpos se pueden detectar en pacientes con neuritis óptica recurrente sin mielitis, así como también en casos con un solo ataque de mielitis aguda sin neuritis óptica; son un marcador muy sensible y específico ${ }^{2}$.

Hasta el año 2006 se contaba con criterios de diagnóstico (Ver Tabla 1), el cumplimiento de estos criterios establecía una sensibilidad del 99\% y una especificidad del $90 \%$; pero debido a la heterogeneidad de presentación y amplitud en las características clínico-radiológicas de la ya estudiada NMO, actualmente se denominan NMOSD ${ }^{1,2,8}$; donde se desarrollaron criterios tanto para NMOSD con AQP4-IgG y NMOSD sin AQP4-IgG. Una categoría adicional de NMOSD con el estado desconocido AQP4-IgG puede ser utilizado para pacientes en los que las pruebas serológicas no está disponible (Ver Tabla 2), y en este caso corresponde al último ya que en Bolivia y la mayor parte de Sudamérica no se cuenta con este tipo de prueba. Según estos criterios en este caso tales individuos deben experimentar 2 o más características clínicas diferentes centrales (es decir, la difusión en el espacio, que afectan a diferentes regiones neuroanatómicas) y otras características de RM de apoyo destinadas a mejorar la especificidad del diagnóstico también debe estar presente. $\mathrm{Al}$ menos uno de los eventos clínicos debe ser una de las 3 características clínicas más comunes de NMOSD: neuritis óptica, mielitis transversa, o un síndrome clínico área postrema (requisito adicional: lesión de la RM medular asociada)1. En este caso la RM muestra: lesión extensa laminar en médula de D6-D9 y otra de D9-D12 con ausencia de lesiones desmielinizantes en cerebro, además de signos de compromiso central como el Babinsky y el ataque agudo de mielitis; sin embargo, ante la sospecha de lesión a nivel del nervio óptico, se realizó una prueba de potenciales evocados visuales donde se evidenció que la onda de altitud de p100 estaba con onda de latencia normal descartando le- sión a la vía óptica (Ver Figura 4). Poniéndonos en conflicto debido a que los potenciales evocados son negativos para la cuestión de agudeza visual, por lo tanto deslumbrando la literatura revisada: la afección de la agudeza visual y el daño al nervio óptico junto con la lesión medular puede presentarse de manera conjunta o no. Sin embargo, se ha reportado pacientes con EM que pueden cursar paralelamente con neuritis óptica y ataque parcial de mielitis y tener una RM Cerebral sin anormalidades, cumpliendo con los criterios iniciales de la $\mathrm{NMO}^{6}$, lo cual crea conflictos en el diagnóstico para poder diferenciar estas enfermedades.

Tratamiento después de un ataque agudo: administración de esteroides intravenosos (típicamente $1.000 \mathrm{mg} /$ día de metilprednisolona durante 3-5 días consecutivos), el cual fue administrada en dosis menor en esta paciente con posterior mejoría. Otras medidas a ser tomados en cuenta son: la plasmaféresis: en pacientes que presentan un cuadro grave o si son refractarios al tratamiento con corticoesteroides; $\sin$ embargo, sus efectos no son muy prolongados y los anticuerpos anti-AQP4 se elevan rápidamente después de ella y para prevenir esto se usan combinaciones de inmunosupresores 2 . Otras investigaciones refieren que los esteroides en dosis bajas reducen la tasa de recaídas. La infusión intravenosa de Mitoxantrona parece reducir las recaídas; el Rituximab representa una opción atractiva de tratamiento por su selectiva acción contra las células B (dosis de $375 \mathrm{mg} / \mathrm{m} 2) 2$. Las pautas actuales tienden a recomendar el uso de inmunosupresores antes del diagnóstico definitivo de NMO y después del primer ataque de neuritis óptica o mielitis aisladas en pacientes que sean seropositivos para anti-AQP4. Aunque se ha usado el interferón- $\beta$ en el tratamiento a largo plazo de la NMO, varias reportes de casos en Japón documentan un fracaso en el uso de esta terapia en esta enfermedad, con desarrollo de lesiones intracraneales importantes, por lo que actualmente no se recomienda su uso. Esto, de hecho, representa una diferencia fundamental más entre la NMO y la EM2, 9,10.

La determinación de AQP4 IgG no se realiza en Bolivia, prueba imprescindible para la pesquisa y el diagnóstico definitivo de esta enfermedad neurodegenerativa poco conocida, identificando este caso por métodos de exclusión quedando como diagnostico probable la mielopatía asociada con la enfermedad de Devic. Por lo tanto se llegó a la conclusión de hallar un caso de Devic, pero aún en observación.

Los autores de este caso agradecen al Dr Quezada: Director de la Caja petrolera de Salud por el apoyo en la presentación de este caso. 


\section{REFERENCIAS}

1. Grupo de Trabajo de Enfermedades Desmielinizantes de la Sociedad Venezolana de Neurología. Esclerosis múltiple diagnóstico y tratamiento. VECTRIMS 2015 $4^{\circ}$ Ed: 349-69. Acceso: 15 de Febrero de 2016. Disponible en : http://lactrims.net/download/Libro\%20EM-VI\%20 Edici\%C3\%B3n\%2028-5-15.pdf

2. Chiquete E, Navarro J, Ayala R, Gutiérrez N, Solórzano A, Rodríguez D y col. Neuromielitis óptica: actualización clínica. Rev Neurol 2010; 51 (5): 289-294. Acceso : 15 de Febrero de 2016 en: http://www.neurologia.com/pdf/Web/5105/ be050289.pdf

3. Pinzon A, Echeverry $T$ y Rodriguez $A$.Neuromielitis óptica (enfermedad de Devic). Acta Med Colomb . 2010, vol.35,(1): 21-25 Acceso: 15 de febrero de 2016. Disponible en: http://www.scielo.org.co/scielo.php?script=sci_arttext\&pi $d=S 0120-24482010000100005$

4. Espinosa AF, Clifton JF, López L, Navarro E, Villarruel JA, Zermeño J y col. Neuropatía compresiva del nervio peroneo. Orthotips 2014. 10(2):93-98. Acceso: 23 de febrero de 2016. Disponible en: http://www.medigraphic.com/pdfs/ orthotips/ot-2014/ot142e.pdf

5. Granados AM, García L, Ortega C,López A. Enfoque diagnóstico de las mielopatías. Rev Colomb Radiol. 2011; 22:(3):3231-51. Acceso: 23 de febrero de 2016. Disponible en: http://www.webcir.org/revistavirtual/articulos/diciembre11/colombia/col espanol a.pdf

6. Lopategui I, Cervantes M, Pentón G. Neuromielitis óptica. Principales diferencias con la esclerosis múltiple. An. Med. Interna 2008; 25 (6 ):294-6.Acceso: 25 de febrero de 2016. Disponible en: http://scielo.isciii.es/pdf/ami/v25n6/revision1.pdf.
8. Wingerchuk DM, Lennon VA, Pittock SJ, Lucchinetti CF, and Weinshenker BG. Revised diagnostic criteria for neuromyelitis óptica. Neurolog 2006; 66 (10):1485-9. Acceso:

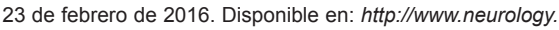
org/content/66/10/1485.full.pdf+html

9. Office of Communications and Public Liaison National.Complicaciones neurológicas del SIDA. Institute of Neurological Disorders and Stroke National Institutes of Health Bethesda 2014.Acceso: 23 de febrero de 2016. Disponible en: http://espanol.ninds.nih.gov/trastornos/Complicaciones Neurologicas_del_SIDA.htm

10. Alemán JM, Alemán VA, Heredia F. Manejo de recaída en enfermedad de Devic. Primer tratamiento exitoso, reportado con plasmaféresis en Ecuador; revisión bibliográfica, actualidad y reporte de caso. Rev Mex Oftalmol 2015; 89(01) . Acceso: 23 de febrero de 2016. Disponible en:http://www.elsevier.es/es-revista-revista-mexicana-oftalmologia-321-articulo-manejo-recaida-enfermedad-devicprimer-90397740

11. Chiquete E, Ochoa A,Navarro J,Gutiérrez P,Ruiz JL. Neuromielitis óptica de Devic: Reporte de caso. Rev Mex de Neurscienc . 2010; 11(3): 234-239.Acceso: 23 de febrero de 2016.Disponible en: http://www.medigraphic.com/pdfs/revmexneu/rmn-2010/rmn103h.pdf 